\title{
LECTURAS CONTEMPORÁNEAS DE CAROLINA CORONADO CON/SIN PERSPECTIVA DE GÉNERO: LAS ESCRITORAS ESPAÑOLAS ANTE LA FLOR ROMÁNTICA
}

\author{
READING CAROLINA CORONADO IN THE XXTH CENTURY \\ WITH/WITHOUT GENDER PERSPECTIVE: \\ SPANISH WOMEN WRITERS \\ IN THE LIGHT OF THE ROMÁNTIC FLOWER
}

\section{Helena ESTABLIER PÉREZ \\ Universidad de Alicante Helena.Establier@ua.es}

Resumen: Este trabajo trata de identificar las primeras discordancias en el recorrido del discurso crítico sobre la obra de la poetisa romántica por excelencia, Carolina Coronado, y relacionarlas con los indicios tempranos de una lectura de sus composiciones con perspectiva de género. Se estudian para ello los ensayos que tres escritoras contemporáneas, Carmen de Burgos, Margarita Nelken y Alfonsa de la Torre, dedican a la poeta extremeña a lo largo de la primera mitad del siglo $\mathrm{XX}$, tratando de revelar cómo en estos ejercicios de crítica literaria paralelos a la tradición vigente, se observan ciertas brechas interpretativas conectadas tanto con la posición autorial periférica de quienes los firman - mujeres inmersas en un contexto literario casi exclusivamente masculino- como con las marcas de género presentes en su objeto de estudio.

Palabras clave: Carolina Coronado. Carmen de Burgos. Alfonsa de la Torre. Margarita Nelken. Lectura. Crítica literaria. Perspectiva de género.

Abstract: This paper focuses on the first mismatches observed in the critical discourse about the Spanish romantic poetess Carolina Coronado, considering them as early signs of the application of a gender perspective 
in the contemporary readings of her compositions. To this end, we consider the essays dedicated to Carolina Coronado by three Spanish women authors - Carmen de Burgos, Margarita Nelken y Alfonsa de la Torre - in the first half of the twenteenth century, and we try to explain their gaps with the standing critical tradition attending to their peripheric position in a male literary context as well as to the gender marks present on the subject of their studies, the poetry of Carolina Coronado.

Key Words: Carolina Coronado. Carmen de Burgos. Alfonsa de la Torre. Margarita Nelken. Reading. Literary criticism. Gender perspective.

\section{INTRODUCCIÓN: LAS POETAS ROMÁNTICAS Y LA LECTURA CON PERSPECTIVA DE GÉNERO}

Desde la última década del pasado siglo, Carolina Coronado ha ido perdiendo el aroma de "flor suave y modesta"1 con el que encandiló a la tradición crítica para ir adquiriendo matices inesperados y revelar aristas más afiladas de lo que su rango de poetisa romántica por excelencia pudiera haber hecho suponer. Hasta entonces y durante más de una centuria, desde la fecha de publicación de sus primeros poemas a finales de la década de 1830 hasta más allá del ecuador del siglo XX, las lecturas de la obra poética de Coronado parecían ser mayoritariamente unívocas. Si bien algunos lúcidos maestros, como el propio Gerardo Diego, habían percibido en fechas bastante tempranas la necesidad de recalar en otras facetas de la extremeña, como su vocación de "poeta responsable" o su consciente feminismo (1962: 394), habría que esperar a las lecturas profundas, sagaces e incisivas que de sus poemas realizaron en los años noventa algunas críticas del hispanismo norteamericano, como Nöel Valis (1990; 1991a; 1991b; 1992) o Susan Kirkpatrick (1989; 1992), y algunos otros del ámbito nacional, como Torres Nebrera (1993), para comenzar a entender que las aguas bajo las cuales descansaba esta "poetisa, flor del lago"2 eran bastante más turbias e inquietantes de lo que a primera vista

\footnotetext{
'Así se la calificaba, de hecho, en la nota que precedía al poema "A la Palma", publicado por vez primera en El Piloto (II) el 22 de noviembre de 1839.

${ }^{2}$ Extraigo el verso de su poema "La flor del agua" (Coronado, 1852: 100).
} 
pudiera parecer.

No podemos olvidar que precisamente por aquellos mismos años cercanos al fin del milenio, la crítica anglosajona se hallaba empeñada en una profusa revaloración y recanonización de las poetas románticas inglesas $^{3}$, a partir de unos principios teóricos que también nos ayudan a comprender la trayectoria seguida por la recepción de nuestras escritoras peninsulares coetáneas. Así, por ejemplo, expresaba Kathleen Hickok, en su interesante ensayo sobre la poesía de la escritora británica Caroline Southey, su propuesta para orientar las estrategias de aproximación crítica a la obra de las románticas: "We should approach the poetry of Romantic women writers with our faculties of judgement strenghened by contemporary theory and not preempted by the vicissitudes of poetic reputation" (1999: 211) [la cursiva es nuestra].

Efectivamente, la reputación poética y el estatus canónico de las románticas inglesas - aspectos sin duda estratégicos para la recepción posterior de cualquier obra literaria- estuvieron garantizados tanto a lo largo de su propia centuria como en las primeras décadas de la siguiente, y sus poemas continuaron durante ese período formando parte de las antologías al uso (Feldman, 1999: 16-21). No en vano "The Poetry of Womanhood and the Affections", como la denominó irónicamente Thackeray (1869: 312), ligada a las emociones y al sentimiento trascendente e impregnada de idealismo, encajaba a la perfección en una cultura victoriana esencialmente conservadora que ensalzaba el valor cívico de las emociones, los afectos domésticos y la piedad religiosa, y que encumbraba la responsabilidad maternal — de las mujeres a la hora de ligar todas esas sensibilidades.

Precisamente las nuevas lecturas finiseculares de la poesía de las románticas anglosajonas - y también, como veremos, las de uno de sus mejores reflejos peninsulares, Carolina Coronado - respondieron a un reposicionamiento crítico respecto a determinados rasgos que habían servido históricamente para diferenciar y encumbrar la producción lírica de estas escritoras, como la sensibilidad y la emoción del yo poético femenino, y también a la intuición de que una lectura cómplice con los silencios, las disonancias y los matices no estudiados de sus poemas podía

${ }^{3} \mathrm{El}$ caudal crítico anglosajón en este terreno es muy extenso. Véanse, por ejemplo, las monografías de M. B. Ross (1989) y de A. Mellor (1993), así como los trabajos colectivos de K. Linkin y S. C. Behrend (1999) y de I. Armstrong y V. Blain (1999). 
revelar en ellos un grado de autoconciencia obliterado por la tradición crítica precedente.

No es casual, desde luego, que este afán resignificador cuajara en la misma época en que, en el citado ámbito crítico anglosajón, se estaba produciendo la formulación conceptual de la lectura con perspectiva de género. Así, en 1982, Jonathan Culler, una de las figuras más relevantes del estructuralismo literario y de la teoría de la lectura, se formulaba la siguiente pregunta:

If the experience of literature depens upon the qualities of a reading self, one can ask what difference it would make to the experience of literature, and thus to the meaning of literature, if this self were, for example, female rather than male. If the meaning of a work is the experience of a reader, what difference does it make if the reader is a woman? (42) [el resaltado es nuestro]

Evidentemente, este interrogante abría la posibilidad de estudiar la incidencia del género sexual en las estrategias de acercamiento al texto literario. También en esa misma década, la confluencia entre las teorías de la recepción y una emergente Crítica Literaria Feminista empeñada en la recuperación y el estudio de la escritura de las mujeres a partir del género sexual, desencadenaba un novedoso interés por desgranar los efectos de este sobre el acto de lectura e interpretación de los textos literarios. Los estudios que abordaron la cuestión desde estas premisas ${ }^{4}$, negaron sistemáticamente la posibilidad de una lectura sexualmente neutra como la que parecía desprenderse de las teorías clásicas de la recepción, asumieron como principio fundamental que las diferencias en la experiencia vital previa y en el punto de vista entre hombres y mujeres repercuten en el proceso de interpretación textual y fijaron una nueva categoría hermenéutica marcada genéricamente: la lectora.

Lo interesante - y también lo más novedoso- de estas nuevas perspectivas de finales de los años ochenta fue no solo el desplazamiento del centro de interés inicial de la Crítica Literaria Feminista - los textos de las escritoras - al sujeto femenino que se enfrenta a la experiencia

${ }^{4}$ Ver, por ejemplo, Kennard (1984), Schor (1985), Flynn y Schweickart (1986), Crawford \& Chaffin (1986), Jacobus (1986), Johnson (1987) y Caughie (1988). 
interpretativa, sino la confluencia inmediatamente posterior de ambas perspectivas, focalizando de forma prioritaria el estudio de los entresijos teóricos de la lectura realizada por las mujeres de los textos escritos por otras mujeres. De esta manera, la revaloración de su producción literaria, consustancial al arranque de la Crítica Literaria Feminista, y el posterior énfasis de esta en el sujeto femenino que lee desde el género, habían ya fraguado, a principios de la década de los noventa, en una categoría integradora de ambas perspectivas, aunque no exenta de claroscuros y contradicciones: las lectoras de textos de mujeres.

Las vías concretas de materialización de esa recién descubierta brecha de género en la lectura variaron en función de la aproximación crítica. Algunas de las aportaciones más relevantes de aquellos primeros años partían de la arriesgada asunción de una experiencia femenina común, que se actualizaría y compartiría en cada acto interpretativo (Flynn \& Schweickart, 1986). Lo que se postulaba, en definitiva, era que la lectura en femenino suponía una hermenéutica positiva de recuperación de la cultura de las mujeres, en la que el texto de una escritora se entendía como un objeto subjetivizado a través del cual ella y su lectora podían encontrarse en una experiencia compartida, como un umbral que, al franquearse, garantizaba la conexión entre ambas (Schweickart, 1986: 51).

Obviamente, aun dentro de un marco general de valoración de las estrategias interpretativas no androcéntricas, estas lecturas empáticas o terapéuticas entre mujeres (Kennard, 1984) no siempre fueron asumidas; de hecho, otras perspectivas, desde posiciones postestructuralistas, rechazaban como objetivo la identificación experiencial entre lectora y autora, y en su lugar avanzaban hacia el reconocimiento y la consolidación de categorías hermenéuticas con claras implicaciones políticas, como la de la lectora feminista - productora de un sistema propio de significados capaces de subvertir las lecturas convencionales o patriarcales sobre las mujeres y deshacer las jerarquías de género tradicionales, en definitiva, la lectora disidente y/o desafiante (Jacobus, 1986; Luna, 1996)—, o la más reciente de lectora nómada, quien en su interpretación del texto literario se ubica entre los códigos semánticos y los procedimientos metodológicos propios de la crítica literaria institucionalizada, por un lado, y los propios del discurso feminista, por el otro (Golubov, 2011).

Pero aun considerando que la formulación conceptual, la reflexión y el debate sobre los fundamentos teóricos, sociales y psicológicos de la 
lectura con perspectiva de género — que, como hemos señalado, facilitaron esas nuevas y profusas aproximaciones al universo poético femenino del Romanticismo a finales del siglo pasado - ha sido una deriva crítica bastante tardía, es evidente que su práctica en la hermenéutica literaria de las mujeres no era ni mucho menos una novedad; baste citar, como ejemplo, a la propia Carolina Coronado, autora de dos paralelos literarios entre Safo y Santa Teresa de Jesús (1850) y de varios ensayos sobre poetisas españolas contemporáneas ("Galería de Poetisas Españolas Contemporáneas", 1857) donde ya hacia mediados del XIX se ejercitaba como crítica literaria de la obra de otras mujeres, como lectora cualificada de otras escritoras.

Con los anteriores puntos de partida, en este trabajo pretendemos explorar la posibilidad de trazar, en la recepción de la poesía de Carolina Coronado, una línea crítica con perspectiva de género, paralela o alternativa a las lecturas que de ella se ofrecieron en las generaciones inmediatamente posteriores a la de la autora extremeña. Para ello, hemos de preguntarnos, en primer lugar, si las escasas mujeres que realizaron crítica literaria en la primera mitad del siglo XX se sintieron apeladas por una poetisa romántica y canónica como Coronado, y en caso afirmativo, explorar qué posiciones adoptaron respecto a la tradición previa, así como cuáles fueron los fundamentos de su opción hermenéutica; saber, en definitiva, si es posible - $\mathrm{O}$ no- identificar brechas de género en la experiencia interpretativa de las lectoras contemporáneas de los versos de Coronado y, si así fuera, analizar en qué medida dichas desviaciones vendrían a perfilar o incluso a desafiar la tradición crítica ya consolidada sobre nuestras poetas románticas.

\section{LA FLOR SUAVE YMODESTA: CAROLINA CORONADO EN LA TRADICIÓN CRÍTICA HASTA 1950}

El proceso de canonización de Coronado comenzó casi en el mismo momento en que la joven poeta de Almendralejo exhaló su primer aliento lírico, en aquellos años en que ya el sobresalto romántico comenzaba a ceder paso a la presencia de la realidad y al intimismo simbólico. La extremeña fue unánimemente aclamada como poetisa desde ese citado poema temprano, "A la Palma", publicado en El Piloto (1839) con una nota elogiosa, posiblemente de Donoso Cortés, que la instituía ya como la "flor suave y modesta que roba al sol del mediodía tan mágicos colores, y 
que embalsama el viento con tan regalados perfumes".

El crítico francés Gustave Deville contribuyó no poco a trazar la senda futura de recepción de la poesía de Coronado cuando la destacaba en su conocido artículo de 1844, "Influencia de las poetisas españolas en la literatura", como "una señora apasionada y entusiasta", con "un talento poético notable" y "un alma poética rica de fuerza, de gracia y de inmortalidad" (195-196), y muy poco después, la revista del editor norteamericano George Graham, Graham's American Monthly Magazine, le dedicaba un largo artículo donde la bautizaba como "the Hemans of Spain" (363), en referencia a la poeta británica Felicia Hemans, tremendamente popular en Inglaterra y en Norteamérica desde los años veinte y considerada por aquel entonces el epítome de la feminidad, de los afectos, de la religiosidad y de la pasión patriótica.

La coronación poética de la joven Coronado en el Liceo Artístico y Literario madrileño el 26 de septiembre de 1848 da buena cuenta de que, por aquellas fechas, se hallaba en la cúspide de su gloria literaria. Los puntales críticos sobre los que se estaba asentando tanto el proceso de construcción intepretativa de Coronado como su reputación poética, fueron los insignes prologuistas de las tres recopilaciones decimonónicas de su obra lírica, vinculados ideológicamente con el liberalismo democrático, al igual que lo estaba la propia familia de la escritora: Juan Eugenio Hartzenbusch, en su prefacio a la primera edición de Poesías de Coronado (1843); el periodista y político progresista Ángel Fernández de los Ríos, en los "Apuntes biográficos de la señorita Carolina Coronado" que precedían al citado prólogo de Hartzenbusch en la nueva recopilación aumentada de $1852^{5}$; y finalmente, en la reedición mejicana de esta última, de 1884, el prefacio de Emilio Castelar que sustituía a los dos anteriores y cuyo contenido ya había sido publicado en La discusión en $1857^{6}$.

Entre los tres trazan, ya en esas décadas centrales del siglo, un perfil poético de la autora unívoco en lo esencial y forjado a partir de unas estrategias críticas comunes: en primer lugar, la elaboración de un recorrido biográfico y de una descripción física, intelectual y moral de Coronado, destinados a acreditarla como modelo de excelsitud femenina

${ }^{5}$ El texto de Fernández de los Ríos ya había sido publicado dos años antes (el 14 de abril de 1850) en el Semanario Pintoresco Español, con el título de "La Srta. doña Carolina Coronado".

${ }^{6}$ Números de 3 de enero, 2 de febrero y 23 de mayo de 1857. 
y al mismo tiempo a resaltar en un tono muy entusiástico, como atributo meritorio, la naturaleza espontánea y escasamente técnica o intelectual de sus composiciones poéticas, productos del espíritu, de la inspiración y de las impresiones de la naturaleza. Las referencias a esa extraña dolencia nerviosa de Coronado, que la dejaba en estado de postración y que llegó incluso a concretarse en 1844 en un sólido rumor sobre su muerte, forman parte también de la construcción de esa imagen poética femenina vinculada a lo subjetivo, a las emociones del alma, inclinada a lo incorpóreo, a lo entrañable, a una "mística armonía" que, en palabras de Castelar, "se siente en todos sus versos" (1884: 17).

Otra de las constantes en el acercamiento de los prologuistas a la obra de Coronado es la traslación de las virtudes íntimas - femeninasde la escritora a su creación literaria, a partir de la identificación y fusión absoluta de la poeta con su obra: "sus versos son ella misma", apunta Hartzenbusch (1843: IX), y Castelar sentencia: “¿Cuál será la poetisa más perfecta? La que mejor conserve y refleje las cualidades de mujer en sus versos. [...] esta poetisa vive entre nosotros y se llama Carolina Coronado" (1884: 9).

Coinciden los tres, por último, en la utilización de los versos de Coronado para enaltecer una "nueva poesía" (Castelar), la "poesía de sentimiento" (Hartzenbusch), que, "en la época más antipoética posible" luce como contrapeso de la pasada exaltación de las pasiones y del creciente materialismo, se asoma a la virtud y a la belleza, en definitiva, "existe entre el alma y Dios" (Fernández de los Ríos, 1852: 1).

Cierto es que los ilustres prologuistas de Coronado detectan también ligeras brechas en esta poesía del corazón, fiel reflejo de la gracia, la dulzura y la inocencia del alma creadora femenina ${ }^{7}$, pero obviamente, estos resquicios incómodos por los que se cuelan las ambiciones literarias de la autora, la expresión exaltada de las pasiones, las reivindicaciones de género y otras notas discordantes en el compacto perfil de la poetisa romántica, quedan oportunamente diluidos, empequeñecidos o atenuados por aquellos otros elementos que, en la estimación de estos críticos, contribuyen a forjar una imagen de Coronado como referente poético y

\footnotetext{
${ }^{7}$ Señala Fernandez de los Ríos, por ejemplo, que "Si alguna vez alza el tono de sus acentos [...] o se indigna hablando del desenfreno de 'El marido verdugo', o hace resonar su lira con el brío y energía de Espronceda [...], pronto recobran sus versos el carácter de dulce melancolía, de candor y ternura que les presta su principal encanto, su gracia, su donaire [...]" (1852: 3).
} 
como modelo de mujer.

Y es que este afán de sublimación con el que se abre la recepción crítica de la obra de Coronado en su propio tiempo, se enmarca, como bien vio Torres Nebrera (1993: 28), en los derroteros del discurso coetáneo sobre las nuevas direcciones que había de tomar la poesía contemporánea en tiempos de crisis, pero también en la ideología de género del nuevo estado liberal, en su inquietud por perfilar los roles sexuales y definir el lugar que en él ocupaban las mujeres. Recordemos que, en 1857, cuando Castelar le dedica a la escritora extremeña sus elogiosísimos artículos en $\mathrm{La}$ discusión, Coronado había optado ya por contener sus ambiciones literarias para dedicarse a la vida familiar y que su voz poética pública desde la compilación de 1852 era cada vez más infrecuente. Precisamente por todo ello, la extremeña es un referente de singular valor ejemplar para aquellos que, como Castelar o Fernández de los Ríos, abogan por un sentido de lo poético en su condición de "expresión más hermosa de lo ideal" (Castelar, 1884: 7), y también, desde las premisas del liberalismo democrático, por un modelo femenino apto para tener una moderada presencia en el ámbito de lo público sin vulnerar los fundamentos del sistema sociopatriarcal decimonónico.

En definitiva, las primeras lecturas de la obra de Coronado, animadas por intereses varios, legitiman su obra y la introducen en el canon poético de su tiempo, pero al ignorar intencionadamente sus disonancias o pulir sus aristas a conveniencia, también orientan y condicionan las bases interpretativas sobre las que habrían de construirse las posteriores valoraciones críticas de la obra lírica de la extremeña. Véanse, si no, los juicios que la autora le merece al padre Blanco García en su estudio sobre La literatura española en el siglo XIX, donde valora especialmente su deriva melancólica y su habilidad para traducir el mundo interior "con femenina delicadeza" (1899: 194). Obsérvese también la condescendencia con la que la contempla Valera en su Florilegio de poesías castellanas del siglo XIX, donde, además de confirmar la excelente reputación poética de Carolina Coronado en su tiempo y de reproducir las valoraciones críticas de Blanco García, concluye calificándola como "la más estimable y simpática de nuestras poetisas líricas" (1903: 312).

Salvando el paréntesis de las dos primeras décadas del siglo 
$\mathrm{XX}^{8}$, marcadas por la deriva purista de la literatura y su consiguiente arrinconamiento de las efusiones del sentimiento (Huyssen, 2006), la corriente neorromántica y rehumanizadora que invade en los años treinta y cuarenta la lírica nacional favorece la revaloración de Carolina Coronado9. No erraba Dionisio Gamallo Fierros cuando en 1944, en un extenso artículo sobre la autora publicado en la recién fundada La Estafeta Literaria, la acreditaba como "dama de moda" $(3)^{10}$, relacionando este interés crítico con la reciente aparición de una biografía sui generis de la poeta escrita por su sobrino nieto, Ramón Gómez de la Serna, quien, en Mi tía Carolina Coronado (1942) se hace buen eco de viejas anécdotas familiares, la presenta como epítome de un romanticismo cursilón y algo trasnochado, y consolida la leyenda de una escritora, como dice Gamallo Fierros, "cataléptica, irónica y sentimental" (1944:13).

En líneas generales, la recepción crítica de la autora extremeña durante esos años primeros de la posguerra, condicionada o no por la peculiar visión de su sobrino nieto, presentó escasas variaciones: la autora seguía vigente única y exclusivamente en el imaginario de los críticos como encarnación de la flor romántica o mitificada por sus peculiaridades biográficas. Buen ejemplo de la pervivencia de esta lectura sesgada y uniforme de Coronado son los artículos de Miguel Muñoz de

\footnotetext{
${ }^{8}$ Solo en torno a 1911 el fallecimiento de Coronado genera una oleada de ensayos laudatorios. Véanse, por ejemplo, el número extraordinario de homenaje póstumo que le dedica la revista Archivo Extremeño en 1911 o el artículo de José Cascales Muñoz en La España Moderna el mismo año. En 1929, la colección "Los Poetas" dedica un número (46) a una breve antología de Carolina Coronado prologada por Teresa de Escoriaza.

${ }^{9}$ Las muestras críticas, ensayísticas y antológicas de esta revaloración del romanticismo decimonónico en los años treinta y cuarenta son numerosísimas (Rivero Machina, 2016: 560632). Las poetisas románticas, aun en menor cuantía, también reciben cierta atención en esos años. Peers, por ejemplo, en su estudio sobre el romanticismo originalmente publicado en inglés en 1940, les dedica un breve capítulo, aunque como sigue de cerca a Blanco García, que es su fuente fundamental, solo contempla a Coronado, a Gómez de Avellaneda y - a vuelapluma - a Massanés. Por su parte, en la antología de Altolaguirre se recogen dos poemas de Coronado ("Rosa Blanca" y "La luna es una ausencia") y uno de Rosalía de Castro ("En las orillas del Sar").

${ }^{10}$ En ese mismo año, por ejemplo, el escritor cordobés Adolfo de Sandoval aprovechaba para relanzar su monografía Carolina Coronado y su época, con escaso eco en su primera edición de 1929; en 1946 se editaba la primera antología contemporánea de poemas de la autora, a cargo del crítico y editor Fernando Gutiérrez González, a la que seguiría, en 1953, la del poeta extremeño Julio Cienfuegos Linares; en 1948, José María de Cossío la había incluido también en su ensayo "Cuatro poetas ante las flores", junto a Francisco de Rioja, Salvador Polo de Medina y Amós de Escalante (85-113).
} 
San Pedro para $A B C$ (1953 y 1967), donde insiste en sus "extravagancias y rarezas" (1953: 21) tanto personales - las reiteradas crisis nerviosas, el afán por conservar insepulto el cadáver embalsamado de su marido, etc.- como ideológicas, resaltando su fervor político a favor de la causa liberal, una "fuerza avasalladora" que al historiador se le antoja chocante e incomprensible en una autora "suave y exquisita" como Coronado (1967: 9).

A la vista de lo expuesto anteriormente, la continuidad y la homogeneidad de las lecturas institucionales de la poesía de Coronado desde los primeros atisbos de su vocación poética en las décadas centrales del XIX hasta casi un siglo después, parecen a primera vista garantizadas. Sin embargo, la introducción de la variable de género en el estudio del proceso de construcción interpretativa de la obra de la poeta extremeña aporta, como veremos, variantes significativas que alteran los resultados de esa línea crítica aparentemente masculinizada y que revelan estrategias de lectura disidentes o, cuando menos, divergentes de la señalada univocidad institucional. Revisaremos, a continuación, los ensayos sobre la poeta extremeña de tres escritoras contemporáneas, Carmen de Burgos, Margarita Nelken y Alfonsa de la Torre, quienes en la primera mitad del siglo XX abordaron críticamente su obra desde posiciones personales, ideológicas y estéticas distintas, pero animadas por idéntico objetivo: enfocar a Carolina Coronado desde otros centros de interés.

\section{UN CEREBRO PRIVILEGIADO. CARMEN DE BURGOS REENFOCA A CORONADO (1917)}

E1 27 de enero de 1917, Carmen de Burgos publica en La Esfera, revista de la que era colaboradora habitual, el artículo "Mujeres intelectuales. Carolina Coronado". Las razones de esta mirada extemporánea sobre la autora extremeña están más relacionadas con la propia biografía de Colombine que con la trayectoria general del discurso crítico sobre la poeta extremeña, que, como hemos señalado anteriormente, pasaba por un momento de letargo en aquella segunda década del siglo. De hecho, un texto casi idéntico al que se reproduce en La Esfera había sido ya incluido por Colombine en su libro de viajes Peregrinaciones (1916). Recogía en él las impresiones de sus viajes por diferentes países europeos (Suiza, Dinamarca, Suecia, Noruega, Alemania, Inglaterra), periplo 
que se cerraba con una última sección dedicada por entero a Portugal. El último capítulo de este extenso libro de viajes se titula precisamente "Carolina Coronado", autora a la que Carmen de Burgos evoca en su paso por Portugal, recordando que fue allí donde la poeta extremeña pasó sus últimos años y también donde falleció en 1911. No es extraño, por otro lado, que Carmen de Burgos recordara en este punto a la autora romántica, pues su compañero en dicho viaje era precisamente el sobrino nieto de Coronado, Ramón Gómez de la Serna.

El retrato que ofrece Carmen de Burgos de Carolina Coronado queda vertebrado no solo por su destacada posición en el mundo de las letras españolas, sino por su condición de precursora, por su extraordinario valor para la tradición histórica de la escritura de las mujeres: "Ella legitimó la inclinación literaria de la mujer hasta el límite que hoy tiene: fue intrépida, decidida y se apasionó del arte con una pasión literaria y fervorosa" (1917: 4). Precisamente la clave diferencial de la visión de Colombine reside en el empeño de conciliar, más aún, de enraizar hasta la médula las facetas de mujer y de escritora de Coronado, desafiando su imagen ya solidificada de poetisa romántica:

Carolina Coronado fue, sobre todo, una mujer, una mujer en la más profunda acepción de la palabra, en sus amores y en sus empresas. Por ser tan mujer se atrevía, cuando no la había influenciado todavía la gazmoñería de su época, a escribir El paralelo de Santa Teresa y Safo, esa obra que después rechazó, pero de la que no pudo extirpar la memoria del título, que se conserva en la galería de los grandes aciertos del pensamiento (1917: 4).

Evidentemente, este afán de Carmen de Burgos por revisitar críticamente a la poeta extremeña requiere un necesario distanciamiento de la identificación tradicional de la poesía femenina con las características esenciales vinculadas a su sexo — gracia, ingenuidad, suavidad, etc.—para perfilar una imagen más poliédrica de la mujer de letras. Por ello, además de insistir en la pasión "honesta, pero fervorosa" con la que Coronado encaró su vida y su obra, y señalar la exuberancia, la intensidad y la originalidad como características fundamentales de su creación literaria, que coexisten en ella con la espontaneidad, la ilusión y la frescura, Carmen de Burgos la describe como "un cerebro privilegiado" (1917: 4), asociación 
metonímica que se desvía sustancialmente de la identificación absoluta de la poetisa romántica con el sentimiento y el corazón postulada por la crítica precedente.

En este sentido, resulta enormemente clarificador que Colombine apenas sobrevuele la elogiadísima y canonizada poesía de Coronado para destacar en su lugar la obra más polémica de la autora, esos arriesgadísmos y pasionales paralelos entre Safo y Santa Teresa que publicó en el Semanario Pintoresco Español en $1850^{11}$, en los que marcaba claras distancias respecto a la interpretación convencional de los escritos de ambas autoras, adoptando - por cierto - una postura bastante crítica con la tradición hermenéutica:

Ahora recuerdo que los escritores que acusan a Safo son los más posteriores a su siglo... Ahora medito en que muchos hombres opinan contra la ilustración del bello sexo, y trabajan por sofocar sus institntos de gloria... Ahora comprendo que también la envidia se apodera de las almas varoniles....

Yo aparto mis ojos de esos ingratos escritos, cierro mis oídos a esos vagos rumores que pretenden deslucir la aureola de Safo, y la veo y la escucho por la visión del entendimiento, y la juzgo por la conciencia del corazón (1850a: 91).

A Santa Teresa no se la puede comprender sino estudiando en sus escritos, sin atender a las interpretaciones y comentarios que tienen la mayor parte de ellos. Los frailes han presentado una Teresa de Jesús que no es la verdadera, porque la verdadera es más fuerte, más grande, más sabia, más sublime, más espiritual y Santa que la que presentan ellos (1850b: 180).

Carmen de Burgos, sin embargo, repara en el valor intelectual de

\footnotetext{
${ }^{11}$ La recepción de los citados artículos de Coronado en el Semanario Pintoresco Español fue bastante controvertida en su tiempo tanto en el plano espiritual como en el literario. Si por un lado la Iglesia reaccionó con no poca virulencia a ese afán de Coronado por equiparar en su ardor pasional a una poetisa pagana, suicida y fogosa con uno de los emblemas del misticismo católico, la elección de un talento nacional como el de Santa Teresa como puntal de la comparación con Safo tampoco convenció en el país vecino, desde el cual la literata Amelie Richard contestó con un artículo bastante crítico, traducido y publicado por el Semanario Pintoresco Español el 23 de junio del mismo año de1850.
} 
ese texto crítico de Coronado, capaz de hacer dialogar sin estridencias a dos escritoras tan aparentemente distantes en lo literario y en lo espiritual como Safo y Santa Teresa de Jesús, y hace pivotar el éxito de este inesperado ejercicio crítico en el género de su autora: "Solo una mujer podía haber visto con tanta claridad ese paralelo tan excesivamente humano" (1917: 4), concluye.

Para Colombine, la Coronado-mujer y la Coronado-escritora siguen siendo un continuum, pero sustentado en unas cualidades - la pasión, la originalidad, el arrojo - absolutamente distantes de las que la convirtieron en un icono del intimismo femenino romántico y que en su lugar le confieren el valor de ser "la encarnación más representativa del romanticismo de su tiempo" así como un modelo autorial de extraordinario valor para la genealogía literaria femenina, el de "la precursora de la mujer que ha de manifestar su alma con valentía en lo porvenir" (1917: 4).

Así, en el artículo de Carmen de Burgos, las limitaciones de Coronado no se explican ni por su talento ni por su inspiración, sino remitiendo a las condiciones materiales en las que desarrolló su actividad literaria, marcadas por el género de la autora: los roles sexuales y familiares, la constricción de su entorno aristocrático y diplomático, la mojigatería ambiental y las autolimitaciones imprescindibles para acomodarse al canon femenino vigente. Si algo le reprocha Colombine es el haber contenido su talento, el no haberlo revelado "empeñándose en el deber más serio, de exaltar la vida entrañable y violenta que vive libremente y con más carácter y más firmeza lejos de los medios cerrados en que vivió". Pese a ello, concluye, "lució con una intensidad que antes que en ella no había lucido nunca en ninguna mujer" (1917: 4).

Esta mirada de Carmen de Burgos en la segunda década del siglo, más atenta a reconstruir la tradición literaria de las mujeres, a postular a Carolina Coronado como un sólido modelo autorial en el que enraizarse, que a presentarla como icono de una variante romántica femenina institucionalizada, era una novedad dentro de las lecturas críticas que la autora extremeña había recibido hasta entonces. No debe sorprendernos, sin embargo, en una autora de la trayectoria de Colombine, absolutamente consciente de las cortapisas que aún en su propio tiempo acechaban a las mujeres de letras y deseosa de legitimar la escritura femenina, de autolegitimarse, en suma, y de componer un canon literario en el que ser mujer no constituyera una variante superflua, sino un accidente de género 
con repercusiones positivas y valiosas sobre la actividad y el producto literarios.

\section{MARGARITA NELKEN CONTRA LA LOA DENODADA- MENTE ENTUSIASTA: CAROLINA CORONADO EN LAS ESCRITORAS ESPAÑOLAS (1930)}

Casi tres lustros después del artículo de Carmen de Burgos, una escritora perteneciente a otra generación, Margarita Nelken (18941968), rescata de nuevo a Carolina Coronado en su ensayo Las escritoras españolas (1930) $)^{12}$.

Para comprender las razones de este libro, no conviene perder de vista que hacia 1928, año en el que Nelken comienza la redacción del trabajo, además de hallarse empeñada en una actividad constante como crítica de arte, sostenía un absoluto compromiso personal tanto con el feminismo como con la literatura ${ }^{13}$, campo este último en el que las mujeres comenzaban a brillar con especial intensidad. Precisamente en ese "actual empuje adquirido por la cultura femenina" (1930: 9) se encuentra el germen del ensayo de Nelken, que trata de recuperar el hilo de la escritura de las mujeres en nuestro país, de trazar su propia genealogía, de encontrarse y de explicar su razón de ser en aquellas otras que desde la Hispania romana hasta los años veinte - la última de las estudiadas es Emilia Pardo Bazán - fueron cimentando una tradición propia de autoría femenina que cuajó en ese extraordinario plantel de narradoras, poetas, ensayistas y dramaturgas de la preguerra en el que se integra también la escritora madrileña.

En su “Introducción”, Nelken explica prolijamente las bases teóricas

\footnotetext{
${ }^{12}$ Un año antes se publica en la colección "Los Poetas" la citada antología de Carolina Coronado prologada por Teresa de Escoriaza (ver nota 8). El prefacio de Escoriaza, donde se congratula de la entrada de las mujeres en la colección, es en realidad una breve nota biográfica de Coronado, a la que cataloga como "la mejor poetisa española" (1929: 5 y 8).

${ }^{13}$ Para esas fechas, Nelken había publicado ya varias novelas breves (La aventura de Roma, 1923; El milagro, 1924; Una historia de adulterio, 1924; Pitimini "étoile", 1924; Mi suicidio, 1924; El viaje a París, 1925; etc.), una novela larga (La trampa del arenal, 1923) y los conocidos ensayos sobre su propio género, La condición social de la mujer en España (1919) y En torno a nosotras (1927). Además, colaboraba en diversos periódicos y revistas con artículos diversos sobre mujeres artistas (Carmen Baroja, Pilar de Zubiaurre, María Rodrigo, etc.) y escritoras, como Josefina de la Torre o Marcelle Capy (Barbero Reviejo, 2015: 346-371).
} 
sobre las que fundamenta esta reconstrucción de una historia literaria nacional en femenino: en primer lugar, ofrecer una visión menos erudita y acumulativa de la cuestión que la pergeñada por los trabajos existentes hasta el momento (1930: 11); a la vista de que los únicos historiadores de la literatura escrita por las mujeres a los que la autora cita en calidad de fuentes son Juan Criado y Domínguez, Diego Ignacio Parada y Manuel Serrano Sanz, no es difícil colegir que esa visión "erudita" y "acumulativa" de la que trata de distanciarse es, también, una visión masculina. En segundo lugar, como alternativa a las citadas historias literarias, Nelken afirma haber procedido con criterios de selección restrictivos, recogiendo en su trabajo solo a aquellas escritoras que le ofrecen "interés literario", "marcado interés histórico" o "interés de curiosidad" por su personalidad (1930: 12). En resumidas cuentas, el propósito de Nelken es la elaboración de un canon propio de escritura femenina en España, basado en criterios absolutamente personales y paralelo a la tradición crítica vigente. El objetivo de su tarea, tal y como ella indica, es reconstruir el ambiente en el que se ha desarrollado esta subcultura literaria femenina, las condiciones que afectan a la escritura de las mujeres, las vicisitudes a las que se ha tenido que enfrentar y los impulsos que la han estimulado (1930: 25); en definitiva, "despertar hacia este ambiente en el lector la misma simpatía que movió a escribir estas páginas", propósito "igualmente ajeno al de la investigación erudita que al de la loa denodadamente entusiasta" (1930: 25).

No obstante, también hallamos en el texto de Nelken posiciones críticas que pueden resultar desconcertantes, como la vinculación directa de la creatividad femenina con la sensibilidad ${ }^{14}$ o la idea de que los productos literarios de las mujeres son inferiores a los de sus colegas varones ${ }^{15}$, lo cual indica que, pese a sus declarados propósitos iniciales, en la aproximación que realiza a sus antecesoras no siempre logra descargarse de las convenciones de la crítica literaria precedente.

En esta sintonía con la tradición crítica incide, desde luego, el que las ideas de Nelken sobre la diferencia sexual sean bastante acordes en lo fundamental a las que a aquélla le habían servido como base para sus

\footnotetext{
14“'Toda la actividad intelectual, toda la capacidad incluso de la mujer española, hállase impulsada o contenida por ese fondo inicial [la sensibilidad]" (1930: 12).

15“Se dirá que no es posible comparar, bajo ningún aspecto, esta producción literaria femenina con la masculina. Desde luego" (1930: 24).
} 
juicios estéticos. Conviene recordar, para comprender mejor las posiciones críticas de la autora ante la literatura de las mujeres y en concreto ante la poesía de Coronado, que su discurso teórico sobre las capacidades artísticas de su sexo, formulado por ella ya en 1930 en diferentes ensayos, descansa sobre un esencialismo complementario muy de época, siempre en complicado equilibrio con su firme defensa de la emancipación femenina, lo cual requiere por su parte ciertos malabarismos para mantenerse fiel a su credo ideológico sin perjudicar los intereses de la causa feminista (Establier, 2004: 58).

En su libro En torno a nosotras (1927), posiblemente el texto más claramente biologicista y determinista de cuantos escribiera Nelken, el temperamento masculino se asocia al campo del espíritu, de la verdad, del conocimiento, de la cultura, del arte y de la capacidad creadora, mientras que lo femenino aparece ligado al sentimiento, al instinto, a la naturaleza y a la conservación. De hecho, en el capítulo XIII, dedicado específicamente a reflexionar sobre "La mujer y el arte", la autora se muestra bastante escéptica sobre las aptitudes de su sexo para la creación artística. Señala, por ejemplo, que las mujeres carecen de capacidad de abstracción (1927: 192) y que su sensibilidad extremadamente desarrollada las faculta más para sentir el arte que para crearlo. La poesía en concreto la entiende Nelken como la actividad artística más próxima a la "emotividad femenina" (1927: 193), y por tanto, uno de los escasos campos artísticos para el que las mujeres tienen condiciones favorables, aunque señala que "la mujer, en cuanto siente con espíritu varonil, apártase de su feminidad, o sea, de su facultad de emoción" (1927: 195). Desde esta premisa, "el arte no es femenino" (1927: 196), entiende Nelken el éxito de las mujeres en el ámbito artístico como una suerte de "condescendencia" masculina, "una corte de honor tácitamente consentida" (1927: 192) ante la cual el personaje que es alter ego de su autora, Isabel, muestra una especial insatisfacción (1927: 192).

Con estas premisas teóricas, y volviendo a Las escritoras españolas, precisamente el penúltimo capítulo del libro lo dedica Nelken a "Las musas románticas", a Gertrudis Gómez de Avellaneda y a "la lira femenina" de Carolina Coronado. Aunque las destaca como "dos de los más esclarecidos poetas líricos de la lengua castellana” (1930: 188), lo cierto es que, a diferencia de la valoración que realiza de la labor poética de la cubana, se muestra bastante severa con la valoración histórica de esos acentos 
“esencialmente" femeninos (1930: 188) de la lira que pulsa Coronado. A la luz de las afirmaciones realizadas en 1927 sobre la condescendencia crítica con las artistas, no nos puede sorprender que Nelken cuestione con acritud los pilares sobre los que se ha forjado históricamente la reputación poética de la extremeña; por un lado, unas cualidades personales y literarias cuyo mérito principal estriba en realidad, en opinión de Nelken, en su esencial diferencia de género: "Esta feminidad de Carolina fue el pedestal más seguro de su gloria. [...] ¿cómo no había de recibir todos los halagos de la gloria si, además, no ofrecía a las liras masculinas motivo de temer se quisiera parangonar con ellas?" (1930: 202-203); y como ejemplos de esta suerte de hiperventilación en la recepción masculina de la poesía de Coronado, recuerda con evidente disconformidad los admirativos juicios que la autora recibe en el citado Florilegio de Valera, donde este la llega a comparar con Santa Teresa, así como los hiperbólicos elogios de Castelar en su prólogo a las Poesías de la autora.

Por otro lado, también advierte Nelken que los triunfos de la extremeña en Madrid, que contribuyeron a su "fulminante celebridad" (1930: 200) e inmediata canonización poética, respondieron más a un ambiente de época, ligado al progresismo europeizante de la España de mitad del XIX y proclive a ensalzar decorativamente la actividad cultural de las mujeres, que a los valores y cualidades literarios de Coronado, los cuales quedan rebajados al nivel de una mera "espontaneidad agradable" (1930: 204). Precisamente esta espontaneidad de la autora extremeña, tan celebrada por Valera y por el resto de críticos precedentes, convertida por todos ellos en seña de identidad y mérito principal de la labor poética de aquélla, es valorada por Nelken en sentido absolutamente contrario, como responsable, por ejemplo, de la afición de Coronado a caminar "por la senda peligrosa de la poesía de circunstancias" (1930: 204) o por la de una emoción patriótica de escaso fundamento ideológico (1930: 201).

La mirada de Nelken sobre Coronado se muestra condicionada por esa concepción esencialista de los sexos que ella suscribe en sus escritos teóricos, idéntica a la que subyace a las críticas decimonónicas de la poeta romántica, pero orientada en su caso a desinflar una tradición de retórica encomiástica sobre la poesía de la extremeña que contribuye a una idealización de las creaciones de las mujeres por el mero hecho de serlo y sin atender a criterios exclusivamente artísticos; por ello, si por un lado señala que "el mérito principal de Carolina residía en sus versos" (1930: 
205) y se refiere admirativamente a algunas de sus composiciones, como "A la Palma" o "El amor de mis amores" — que le parece la más inspirada, la de mayor empeño y la más romántica de la autora (1930: 206)—, al mismo tiempo hay en su aproximación a la extremeña un empeño latente por resaltar, en tono de cierta condescendencia reprobadora, los acentos de esa veta femenina sobre la que se construyó el mito de Coronado, catalogándola como "la poetisa", marcando distancias con los "acentos viriles" de Gertrudis Gómez de Avellaneda o evocando una imagen decorativa, trivial, superflua e incluso rancia tanto de la mujer como de la escritora (1930: 297).

En definitiva, la aproximación de Nelken a la figura de Carolina Coronado se mueve, como su propia ideología sobre la diferencia sexual, en los planos de la tensión y del conflicto interno de la propia artista-feminista que realiza la crítica literaria. La voluntad de rescatar a la poeta romántica y de aceptar la sensibilidad y la espontaneidad como características inherentemente femeninas, coexiste con una cierta irritación, una insatisfacción profunda ante las que ella percibe como limitaciones de la escritora y ante el uso distorsionador que la tradición crítica ha hecho de ellas. Contrariamente a lo que sucede en la lectura que realiza Carmen de Burgos, Nelken, arrastrada y condicionada por la rigidez de sus propias teorías sobre la creatividad femenina, se muestra impermeable a las disidencias, los silencios y las brechas en la poesía de Coronado, lo cual genera en ocasiones una visión exenta de matices y sorprendentemente plegada a la interpretación convencional sobre aquella, perspectiva de la que solo se desvía para cuestionar las cualidades poéticas de la autora extremeña - a la que considera hipervalorada precisamente por haber llevado a su obra los acentos femeninos que emanan de su propia condición sexual-, es decir, para distanciarse de los riesgos de esa "loa denodadamente entusiasta" (1930: 25) que achacaba en su "Introducción" al tradicional acercamiento masculino a la literatura escrita por las mujeres.

\section{LOS NUEVOS MATICES DE LA FLOR ISABELINA EN LA POSGUERRA. ALFONSA DE LA TORRE RELEE A CORONADO (1944)}

En 1944, en plena recuperación de la figura de Coronado, 
una joven poeta, Alfonsa de la Torre (1915-1993) ${ }^{16}$ dedica su tesis de doctorado a la autora extremeña, bajo el revelador título de Carolina Coronado, poetisa romántica. Posiblemente, algunas de las razones que la condujeron hasta Coronado fueron, tal como explica María Payeras, la oportunidad académica - ya hemos señalado el renacimiento del interés por la autora a partir del libro de Gómez de la Serna de 1942 - y una cierta relación "especular" con su objeto de estudio, en virtud de ciertas afinidades poéticas y personales (Payeras, 2017: 101; 106-108). Con toda certeza, el trabajo de Alfonsa de la Torre se enmarca también en esa ya señalada deriva neorromántica y rehumanizadora de la literatura, que arranca de mediados de la década anterior y que continúa en la de los cuarenta, centrada, en lo que a magisterio y a modelos poéticos respecta, en una revaloración y una reinterpretación de la poesía de Bécquer como máxima expresión de un romanticismo de lo íntimamente personal, lo inefable y lo sencillo, alejado de los gestos grandilocuentes y ampulosos de otras manifestaciones decimonónicas de esta corriente estética (Rivero Machina, 2016: 560-632).

La reivindicación de la contemporaneidad de Bécquer y de su romanticismo intimista y humano frente al academicismo, por un lado, y a la trasgresión lúdica de las vanguardias, por otro, mantuvo su proyección a lo largo de los años cuarenta hasta el medio siglo. Precisamente en 1939, Joaquín de Entrambasaguas, director de la tesis de Alfonsa de la Torre, postulaba la modernidad de lo romántico: "lo clásico o lo humano [...] como se entiende hoy, comienza a depurar nuestra vida, y apoyará, como siempre, nuestras mejores actitudes románticas, salvándolas de la exaltación pasajera" (22); en esta misma línea Dámaso Alonso reclamaba "la originalidad de Bécquer" en su ensayo del mismo título, y tanto él en este trabajo de 1944 (261-304) como Luis Cernuda años más tarde (1957) coincidían en presentarlo como el portón de entrada a nuestra contemporaneidad lírica.

En este contexto debemos entender el esfuerzo de Alfonsa de la Torre, alumna de Dámaso Alonso y de Entrambasaguas (Payeras, 2018: 858), por reenfocar la imagen poética de Carolina Coronado y elevarla

\footnotetext{
${ }^{16}$ La tesis, dirigida por Joaquín de Entrambasaguas, se presenta en la Universidad Central, bajo el auténtico nombre de la poeta, Ildefonsa Torre de Rojas. Se encuentra en la Biblioteca de la Universidad Complutense.
} 
al estatus de icono de la poesía romántica. De hecho, en las primeras páginas, la autora reconoce como objetivo de su estudio el de responder críticamente a la mitificación experimentada por la figura de Coronado a efectos tanto de la reciente biografía de su sobrino nieto vanguardista — dice la autora, "envuelta en greguerías" (1944: 194), llena de errores y de falsas interpretaciones (1944: 4) - como de la actualización contemporánea de la poeta por obra del "revuelo de elogios" de los que denomina "neblíes filorrománticos" (1944: 3). De la Torre expresa su voluntad de contrarrestar con su investigación el riesgo de que la falsa popularidad de Coronado, desdibujado el auténtico yo detrás de su "silueta romántica", pueda ir en detrimento de su valoración literaria (1944: 194). No en vano las primeras páginas del ensayo constituyen una suerte de aproximación irónico-crítica de la autora a la visión estereotipada de la época romántica - con sus cornucopias, sus porcelanas, sus redecillas y sus guardapolvos - y de la propia Coronado, esa "flor romántica", cuyo nombre, dice De la Torre, "parece salido de un marcador de nombres para bordar pañuelos, y tiene la fonética monjil, entrecortada de los nombres pronunciados clandestinamente por colegialas en sus corrillos" (1944: 2-3).

Aparentemente, la intención de Alfonsa de la Torre responde a intereses similares a los de Nelken en su libro sobre Las escritoras españolas, el cual aparece puntualmente recogido en su bibliografía final: descanonizar a Carolina Coronado, ofrecer de su obra "una nueva interpretación adaptada a nuestro gusto moderno" (1944: 2). Este objetivo requiere hacer brillar la "naturaleza verdad" de la autora (1944: 138) frente a los tópicos, o dicho con otras palabras, completar su imagen sesgada de poetisa romántica con los rasgos que, a su juicio, son identificativos de la lírica femenina moderna: la violenta sinceridad y la natural y apasionada expresión (1944: 195).

Pero lo cierto es que, pese a esta declaración de buenas intenciones críticas, la afirmación, apenas iniciado el ensayo, de que la vida de Carolina "fue una sublimación literaria de su obra" (1944: 3), ya nos sugiere que quizá su objetivo incial quede distorsionado por una hipervaloración de esos mismos aspectos emocionales, anecdóticos y subjetivos que pretende deslegitimar. Y efectivamente, las vías que recorre la tesis doctoral de la joven poeta segoviana, lastrada por la voluntad de recuperación de la faceta más humana de Carolina Coronado y por un biografismo muy de época, 
se desvían con mucho de su intención inicial para acabar recorriendo con complacencia los tópicos que configuraron la imagen personal y la reputación poética de la escritora romántica durante casi un siglo. En este sentido, una de las estrategias hipervalorativas más frecuentadas por la crítica decimonónica sobre Coronado, el examen minucioso del sujeto poético - de sus avatares biográficos, del perfil psicológico-emocional y del cuerpo femenino que lo encarna-, que reemplazaba a la lectura profunda y a la indagación en los matices de su creación literaria, atraviesa también todo el ensayo de Alfonsa de la Torre, que no es sino una reconstrucción subjetiva, libre e imaginativa — casi novelada - de la personalidad y de la vida de Coronado a partir de la lectura de sus poemas en clave biográfica. Tanto es así que de los veintidós capítulos que conforman este trabajo, veintiuno se dedican a trazar un perfil y una trayectoria vital de la autora a partir del contenido de sus composiciones poéticas, y solo uno, el último, ensaya en apenas cuatro páginas un somero ejercicio de crítica literaria.

El foco de la atención de Alfonsa De la Torre, la vía por la que pretende pulir esa imagen estereotipada de Coronado hecha "flor isabelina de suspiros y tirabuzones" (1944: 2), lo constituyen sus rasgos psicológicos y emocionales. Por ello, el trabajo se esfuerza en acentuar con especial hincapié el "temperamento ardiente, impresionable, dominador" de Coronado a través de la vertiente más íntimamente pasional de su poesía, más transgresora, sus "poemas eróticos" (1944: 99), por ejemplo, cargados de una "violenta pasión que la hace arder con temblores de llama y consumirse y palidecer como seca hierba" (1944: 105), su "desbordante sensualidad" que "se escapa en jirones de apasionadas estrofas" (1944: 155), o esa vertiente de su poesía religiosa cargada de amargura y de imprecaciones a Dios, y que excede, como bien ve De la Torre, los límites del decoro en aquella posguerra oscura y timorata (1944: 72).

Esos nuevos perfiles de la poesía de Coronado, invisibilizados por la crítica anterior, son, posiblemente, la mejor aportación del estudio de Alfonsa de la Torre. Sin embargo, este afán de matizar con las turbulencias del alma la imagen "delicada, inspirada, tierna, sensible, encantadora, eminente, célebre, ilustrada, poetisa" (1944: 75) de la extremeña, también conduce a Alfonsa de la Torre a resaltar en su estudio precisamente aquellas peculiaridades de su carácter - manías, rarezas, crisis nerviosas y catalepsias, etc. - que ya la crítica decimonónica justificaba como manifestación de su valorada sensibilidad femenina. A fuerza de insistir 
en el camino de la biografìa emocional, el estudio de De la Torre acaba por cincelar la imagen de una Coronado "histérica" (1944: 96), con "sensibilidad de vidente" (1944: 116), "fuera de la realidad" (1944: 152), embargada por pasiones violentas y superada por su propia "megalomanía" (1944: 152). Todos esos elementos no son, para la autora del trabajo, sino pruebas fehacientes de una actitud literaria ante la vida (1944: 145) que confirma a Coronado como "la representación más genuina de la poesía romántica" (1944: 188).

En definitiva, en su deseo de hacer trascender la imagen de Coronado más allá de los tópicos románticos al uso, de superar una visión parcial de la autora, Alfonsa de la Torre la aprisiona en otros muchos. Si bien percibe con claridad que aquella célebre afirmación de Hartzenbusch, "sus versos son ella misma", fue "el pedestal sobre el que se asentó el ídolo de feminidad literaria ante el que los escritores contemporáneos quemaron el incienso de sus adjetivos" (1944: 74-5), lo cierto es que en su propio estudio no logra evitar que la poeta romántica y su obra queden fundidas en amalgama indesligable, convertida la última en una mera prolongación y a la vez un espejo de la primera, de su cuerpo y de su alma. Espíritu, carne y poesía femeninos, ya un todo compacto y sólido en la crítica precedente, vienen a confirmarse como tales en el trabajo de Alfonsa de la Torre, que, en sus últimas páginas, dedicadas a realizar una valoración global de la obra de Coronado, se pliega a las visiones más convencionales de esta, recalcando su ternura, su "gracia femenina", su voz, "arrullo de tórtola y frescura de manantial", para concluir que Carolina fue "una inmensa flor de poesía, un pájaro solitario que a las orillas del Gévora cantó amores y sueños" (1944: 197).

Con gran acierto observa María Payeras que Alfonsa de la Torre no advierte, por ejemplo, la vertiente "feminista" de Coronado (2017: 108). Efectivamente, no encontramos en su análisis más que una ocasional referencia a su relación con otros "ruiseñores" de su tiempo (1944: 89-90), y tampoco lecturas de aquellos poemas de la primera época de Coronado en los que esta expresaba con meridiana claridad su disconformidad con algunos de los fundamentos sociofamiliares del patriarcado, pero lo cierto es que ni las fuentes en las que Alfonsa de la Torre bebe para su investigación, ni la historia literaria precedente, ni su entorno académico, le facilitan unas prácticas de lectura disidentes o le muestran las vías por las que contemplar la obra de la poeta romántica desde otra posición crítica. 
El trabajo de Alfonsa de la Torre sobre Coronado viene así a confirmar esa relación ambigua, de atracción y rechazo, que la acreditada reputación poética de la extremeña como poetisa romántica parece generar entre ella y las críticas contemporáneas, pero sin duda representa también un primer esfuerzo claro - aunque no siempre exitoso - de superar la uniformidad de los juicios sobre su obra para tratar incorporar nuevas dimensiones a su perfil poético.

\section{A MODO DE CONCLUSIÓN: LAS ESCRITORAS CONTEMPORÁNEAS, CAROLINA CORONADO Y EL SÍNDROME DE JANO}

A través de los ensayos de Carmen de Burgos, Margarita Nelken y la propia Alfonsa de la Torre, en las páginas precedentes hemos constatado que, pese a las obvias variantes en la aproximación de las críticas contemporáneas a la poesía de Coronado, también es posible identificar estrategias comunes. La propia selección del objeto de estudio, la voluntad compartida de acercamiento a la autora, revelan una inquietud más o menos explícita por la tradición literaria femenina, por construir una subcultura a través de la cual autoexplicarse y justificar su propia existencia. No en vano, y simplemente como escritoras que desarrollan su profesión en un campo literario fundamentalmente masculino, las tres sostienen ya una posición conflictiva con la historia literaria, con la crítica literaria institucionalizada y con el mismo canon; es comprensible, por tanto, que la reputación poética consolidada de Coronado en una tradición poco proclive a destacar las cualidades artísticas de las mujeres, produjera en estas escritoras contemporáneas, sometidas a las tensiones de su doble condición de mujeres y creadoras, una cierta fascinación, e incluso actuara como estímulo para tratar de desgranar las claves de este fenómeno inusual. Al mismo tiempo, las tres lo contemplan con cierto escepticismo, conscientes de los riesgos implícitos en esa misma reputación poética en clave de género, y por ello tratan o de ajustar o rebajar la valoración crítica precedente, o incluso de desviar el foco de atención hacia otras lecturas, otros matices que permitan ofrecer una imagen más plural, más poliédrica, con más dimensiones que la de la flor romántica. Y para ello, hijas del mismo sindrome de Jano que legitima su existencia contradictoria, siguen perpetuando ciertos tópicos sobre la escritura de las mujeres. 
Si contemplamos con cierta perspectiva histórica el acercamiento de las críticas a los textos de otras mujeres, comprobaremos que no siempre se ha conseguido - o querido - eludir las prácticas interpretativas institucionalizadas, aquellas que las críticas feministas identificaron como estrategias de lectura androcéntricas. No es infrecuente en la historia de nuestra crítica literaria el que las lectoras de textos de mujeres hayan evitado más o menos conscientemente los sesgos de género o incluso que hayan sido abiertamente críticas con aquellos aspectos de la obra estudiada que revelaban conscientemente la identidad genérica de sus autoras, quizá haciendo suya la máxima de Doña Emilia acerca de que en el terreno literario no hay varones ni hembras (cit. por Bieder, 1993: 19) o la de Virginia Woolf, cuando indicaba que quienes escriben "no son hombres, no son mujeres. Se dirigen hacia esa amplia zona del alma que carece de sexo..." (Woolf, 1981: 83).

Quizá por ello, y desde hace más de cuatro décadas, la Crítica Literaria Feminista venga profundizando en las razones por las cuales no siempre se observan diferencias sistemáticas en las estrategias interpretativas de las mujeres y de los hombres. De hecho, la teoría del grupo silenciado de Shirley Ardener ${ }^{17}$ (1975) constituyó en su momento un interesante fundamento para sostener la idea de que las escritoras y las lectoras, en su deseo de acomodación social, adoptan los modelos de expresión y de interpretación - masculinos - recibidos y de este modo participan en la canonización de textos androcéntricos y en la marginación de los que no lo son (Crawford y Chaffin, 1986: 23). Con esta rotundidad, por ejemplo, lo expresaba Judith Fetterley en su interesante trabajo The Resisting Reader: "As readers and teachers and scholars, women are thaught to think as men, to identify with a male point of view, and to accept as normal and legitimate a male system of values [...]" (1978: XX).

Quizá las aproximaciones de las escritoras contemporáneas a Carolina Coronado respondan parcialmente a estas posiciones de sujeto lector institucionalizado, pero en cualquier caso parece innegable que en sus ensayos también es posible identificar brechas que se explican desde su condición sociocultural de mujeres que escriben, y que implican la

\footnotetext{
${ }^{17}$ Dicha teoría identificaba una desventaja en los grupos humanos sometidos o acallados a la hora de articular su experiencia usando un lenguaje derivado de las percepciones del grupo dominante (Ardener, 1975).
} 
aplicación de la perspectiva de género cuando este concepto ni siquiera había sido formulado. Si en líneas generales el devenir de nuestra estética y nuestra crítica ha ignorado las diferencias de género, o bien al contrario, como ejemplifica el caso de Coronado, las ha agudizado y sobrevalorado como estrategia de contención de lo femenino, las primeras lectoras contemporáneas de la escritora extremeña, con sus limitaciones y sus divergencias, las sometieron ya a reflexión y a análisis en sus ensayos, las visibilizaron, las cuestionaron y/o las legitimaron, abriendo así en nuestro país las más tempranas vías de reinterpretación de la poesía femenina romántica.

\section{REFERENCIAS BIBLIOGRÁFICAS}

ALONSO, D. (1944). “Originalidad de Bécquer”. En Ensayos sobre poesía española, 261-304. Madrid: Revista de Occidente.

ALTOLAGUIRRE, M. (1932). Antología de la poesía romántica española. Madrid: Espasa-Calpe.

Archivo Extremeño (1911). Número extraordinario en homenaje a Carolina Coronado. Febrero-marzo.

ARDENER, S. (1975). Perceiving Woman. London: Malaby Press.

ARMSTRONG, I. \& BLAIN, V. (1999). Women's Poetry. Late Romantic to Late Victorian: Gender and Genre 1830-1900. Basingstoke: MacMillan.

BARBERO REVIEJO, T. (2015). Margarita Nelken (Madrid 1894, México D.F.1968). Compromiso político, social y estético. Tesis Doctoral: Universidad de Barcelona.

BIEDER, M. (1993). “Emilia Pardo Bazán and Literary Women. Women’s Reading Women's Writing in Late 19th-Century Spain". Revista Hispánica Moderna XLVI, 19-31.

BLANCO GARCÍA, F. (1899). La literatura española en el siglo XIX. Vol. I. Madrid: Sáenz de Jubera Hermanos.

BURGOS, C. de (1917). "Mujeres intelectuales. Carolina Coronado". La Esfera 161, 27 de enero, 4.

CASCALES MUÑOZ, J. (1911). "Carolina Coronado: su vida y sus obras". La España Moderna 268, abril, 40-65. 
CASTELAR, E. (1884). "Carolina Coronado". En Poesías completas de Carolina Coronado, 7-27. México: Imprenta de la Librería Hispano-Mexicana.

CERNUDA, Luis (1957). Estudios sobre poesía española contemporánea. Madrid: Revista de Occidente.

CIENFUEGO LINARES, J. (1953). Poesias de Carolina Coronado. Badajoz: Arqueros.

CORONADO, C. (1850a). "Los genios gemelos. Primer paralelo. Safo y Santa Teresa de Jesús". Semanario Pintoresco Español, 24 de marzo, 89-94.

(1850b). "Los genios gemelos. Notas para la mejor inteligencia del paralelo de Safo y Santa Teresa de Jesús". Semanario Pintoresco Español, 9 de junio, 178-180.

(1852). Poesías. Madrid: [s.n.].

COSSIO, J. M. de (1948). "Cuatro poetas ante las flores”. Finisterre 42, octubre, 85-113.

CRAWFORD, M. \& CHAFFIN, R. (1986). “The Reader's Construction of Meaning: Cognitive Research on Gender and Comprehension". En Gender and Reading, E. A. Flynn \& P. P. Schweickart (eds.), 3-30. Baltimore: John Hopkins UP.

CULLER, J. D (1982). On deconstruction: Theory and Criticism after Structuralism. Ithaca: Cornell UP.

DEVILLE, G. (1844). "Influencia de las poetisas españolas en la literatura". Revista de Madrid II, 190-199.

DIEGO, G. (1962). "Primavera de Carolina Coronado". Boletín de la Biblioteca Menéndez Pelayo XXXVIII, 385- 409.

ENTRAMBASAGUAS, J. de (1939). La determinación del Romanticismo español y otras cosas. Barcelona: Apolo.

ESCORIAZA, T. de (1929). "Carolina Coronado o la mejor poetisa española". En Antología, Carolina Coronado, 5-8. Colección "Los Poetas", 46, año II, 22 de junio.

ESTABLIER PÉREZ, H. (2004). "El feminismo español en la narrativa de los años veinte: Margarita Nelken y La trampa del arenal". Clepsydra 3, enero, 47-66.

FELDMAN, P. R. (1999). "Endurance and Forgetting. What the Evidence Suggests". En Romanticism and Women Poets. Opening the Doors of Reception, H. Kramer Linkin \& S. C. Behrend (eds.), 16-21. 
Lexington, Kentucky: The University Press of Kentucky.

FERNÁNDEZ DE LOS RÍOS, Á. (1852). “Apuntes biográficos de la señorita doña Carolina Coronado". En Poesías, Carolina Coronado, 1-4. Madrid: [s.n.].

FETTERLEY, J. (1978). The Resisting Reader: A Feminist Approach to American Fiction. Bloomington: Indiana UP.

FLYNN, E. A. \& SCHWEICKART, P. P. (eds.) (1986). Gender and Reading. Baltimore: John Hopkins UP.

GAMALlO FIERROS, D. (1944). "Doña Carolina Coronado. Dama de moda". La Estafeta Literaria, 15 de abril, 3.

GOLUBOV, N. (2011). "La teoría literaria feminista y sus lectoras nómadas". Discurso, teoría y análisis 31. https://www.academia. edu/666545/La_teoría_literaria_feminista_y_sus_lectoras_ nómadas [11/11/2018]

GÓMEZ DE LA SERNA, R. (1942). Mi tía Carolina Coronado. Buenos Aires: Emecé.

GRAHAM, G. (1851). "Modern Spanish Literature, Carolina Coronado". Graham's American Monthly Magazine XXXIX, diciembre, 360364.

GUTIÉRREZ GONZÁLEZ, F. (1946). Antología poética, Carolina Coronado. Barcelona: Montaner y Simón.

HARTZENBUSCH, J. E. de (1843). "Introducción”. En Poesías de la señorita doña Carolina Coronado, I-XII. Madrid: Imprenta de Alegría y Charlain.

HICKOK, K. (1999). "Burst Are the Prison Bars. Caroline Bowles Southey and the Vicissitudes of Poetic Reputation". En Romanticism and Women Poets. Opening the Doors of Reception, H. Kramer Linkin \& S. C. Behrend (eds.), 192-213. Lexington, Kentucky: The University Press of Kentucky.

HUYSSEN, A. (2006). Después de la gran división. Modernismo, cultura de masas y postmodernismo. Buenos Aires: Adriana Hidalgo Editora.

JACOBUS, M. (1986). Reading Woman: Essays in Feminist Criticism. New York: Columbia UP.

JOHNSON, B. (1987). A World of Difference. Baltimore: John Hopkins UP.

KENNARD, J. E. (1984). “Ourself behind Ourself: A Theory for Lesbian 
Readers”. Signs 9.4, Summer, 647-662.

KIRKPATRICK, S. (1989). "Waterflower: Carolina Coronado's Lyrical Self-Representation". En Las Románticas: Women Writers and Subjectivity in Spain, 1835-1850, 208-243. Berkeley: University of California Press.

(1992). “Introducción”. En Antología poética de escritoras del siglo XIX, 7-63. Madrid: Castalia / Instituto de la Mujer.

LUNA, L. (1996). "Leyendo como una mujer la imagen de la mujer". En Leyendo como una mujer la imagen de la mujer, 11-27. Barcelona / Sevilla: Anthropos / Instituto Andaluz de la Mujer.

MUÑOZ DE SAN PEDRO, M. (1953). "Carolina Coronado. Notas y papeles inéditos". Índice de Artes y Letras 64, XLIII, junio, 1 y 21-22.

(1967). "Las ideas políticas de Carolina Coronado". $A B C, 6$ de julio, 9.

NELKEN, M. (1927). En torno a nosotras. Madrid: Páez.

(1930). Las escritoras españolas. Barcelona: Labor.

(1975). La condición social de la mujer en España. Madrid: CVS [1919].

PAYERAS GRAU, M. (2017). “Escritoras en diálogo (Alfonsa de la Torre, Carolina Coronado y Luisa Sigea)". Revista de Escritoras Ibéricas 5, 93-122.

(2018). "Claves para la lectura de Oratorio de San Bernardino, de Alfonsa de la Torre". Signa 27, 857-882.

PEERS, E. A (1967). Historia del movimiento romántico español, 2 vols. Madrid: Gredos.

PÉREZ GONZÁLEZ, I. M.(1999). Carolina Coronado (Del Romanticismo a la crisis fin de siglo). Badajoz: Diputación Provincial.

RICHARD, A. (1850). "Sobre el paralelo de Safo y Santa Teresa". Semanario Pintoresco Español, 23 de junio, 193-194.

RIVERO MACHINA, A. (2016). Más allá de la posguerra. Poesía y ámbito literario (1939-1950). Tesis Doctoral: Universidad de Extremadura.

SANDOVAL, A. de (1944). Carolina Coronado y su época. Zaragoza: Librería General.

SCHOR, N. (1985). Breaking the Chain: Women, Theory and French Realist Fiction. New York: Columbia UP. 
THACKERAY, W. M. (1869). The Newcomes. Memoirs of a Most Respectable Family, vol. II. London: Smith, Elder and Co.

TORRE, A. de la (1944). Carolina Coronado, poetisa romántica. Memoria para optar al grado de Doctor. Universidad Central de Madrid.

TORRES NEBRERA, G. (1993). "La obra poética de Carolina Coronado". En Carolina Coronado. Obra poética, vol. I, 11-99. Mérida: Editora Regional de Extremadura.

VALERA, J. (1903). Florilegio de poesías castellanas del siglo XIX, vol. V. Madrid: Librería de Fernando Fé.

VALIS, N. (1990). "The Language of Treasure: Carolina Coronado, Casta Esteban and Marina Romero". En In the Feminine Mode, Essays on Hispanic Women Writers, N. Valis \& C. Maier (eds.), 246-272. Lewisburg: Pennsylvania, Londres: Bucknell University Press. (1991a). "Introducción". En Poesías, Carolina Coronado, 7-41. Madrid: Castalia / Instituto de la Mujer. (1991b). "La autobiografía como insulto". En La autobiografía en la España contemporánea. Anthropos 125, 36-40. (1992). "La segunda sombra de Carolina Coronado", Revista de Estudios Extremeños XLVIII, 2, 541-554.

WOOLF, V. (1981). Las mujeres y la literatura. Barcelona: Lumen.

Recibido el 8 de enero de 2019.

Aceptado el 12 de marzo de 2019. 